\title{
Performance Evaluation of a Novel Cross-laminated Timber Made from Flattened Bamboo and Wood Lumber
}

\author{
Peixing Wei, ${ }^{\mathrm{a}, \mathrm{b}, *}$ Brad Jianhe Wang, ${ }^{\mathrm{c}}$ Hao Li, ${ }^{\mathrm{d}}$ Libin Wang, ${ }^{\mathrm{d}}$ Yingchun Gong, ${ }^{\mathrm{e}}$ and \\ Suyong Huang $\mathrm{f}$
}

\begin{abstract}
A novel flattened bamboo-wood composite cross-laminated timber (CCLT) made from flattened bamboo and hemlock lumber was developed, and its mechanical performance was investigated and quantified in this work. The results demonstrated that the CCLT columns and control hemlock CLT counterparts had nearly equal axial compression strength, but the CCLT yielded a higher compression modulus of elasticity (MOE). Additionally, the CCLT compression behaviors were not significantly affected by the height. Compared with hemlock CLT, the CCLT exhibited a slightly higher flatwise bending $\mathrm{MOE}$ and strength in the major strength direction. Furthermore, the MOE and strength of the CCLT under edgewise bending were $17.3 \%$ less and $16.2 \%$ greater than those under flatwise bending, respectively. The load-carrying capacity of the CCLT was mainly governed by the interfacial failure between the bamboo and wood, in which no rolling shear failure was observed. Those features are unique for the new CCLT for engineered applications.
\end{abstract}

Keywords: Composite cross-laminated timber (CCLT); Flattened bamboo; Hemlock; Axial compression; Bending

Contact information: a: School of Civil Engineering, Southeast University, 210096, PR China; $b$ : School of Landscape Architecture, Jiangsu Vocational College of Agriculture and Forestry, Jurong 212400, PR China; c: Ningbo Sino-Canada Low Carbon New Technology Institute, Ninghai 315600, PR China; d: School of Civil Engineering, Nanjing Forestry University, Nanjing 210037, PR China; e: Research Institute of Wood Industry, Chinese Academy of Forestry, Beijing 100091, PR China; f: College of Material Science and Engineering, Southwest Forestry University, Kunming 650224, PR China;

* Corresponding author: wayne0448123@163.com

\section{INTRODUCTION}

The application of cross-laminated timber (CLT) has rapidly increased in Europe and North America since 1990 (Brander et al. 2016). CLT is a large-dimension massive timber panel made by bonding 3 to 7 layers of kiln-dried dimensional lumber or structural composite lumber (SCL), wherein each layer is oriented orthogonal to the adjacent layer (i.e., cross-laminated). The CLT is usually prefabricated into wall, floor, and roof elements according to design requirements. This product has many advantages, including having a light weight, high strength, good thermal insulation, good sound insulation, and durability as well as easy assembly. Therefore, CLT can be seen as a new construction material that can replace traditional construction materials (such as steel, concrete, and masonry) (Davids et al. 2017). The development and application of CLT has become a hot spot in the fields of new construction materials and civil engineering. At present, CLT is primarily produced from coniferous species such as spruce and fir (ANSI/APA PRG 320 2019). Although softwood CLT can meet the requirements of design specifications, there are inherent defects in the raw materials, such as low rolling shear resistance, especially in the 
transverse direction (Davids et al. 2017). Timber structure buildings have moved from lowrise to middle or high-rise worldwide in the past few years, which requires high end costeffective CLT products (Chen et al. 2016; He et al. 2016; Zhou et al. 2017a). Hence, finding a method to use local species to make competitive CLT products has generated a great interest. In Europe and North America, SCL, such as laminated strand lumber (LSL) (Davids et al. 2017) and laminated veneer lumber (LVL) (Wang et al. 2017), and hardwood species (Liao et al. 2017), such as beech (Espinoza and Buehlmann 2018), have been used for making composite CLT (CCLT). This approach can effectively improve the rolling shear resistance of generic CLT because SCLs have been restructured and hardwood has more complex structure of growth rings, which can hinder the crack development. Chinese scholars have explored the use of domestic fast-growing species, such as larch (Gong et al. 2016), eucalyptus (Liao et al. 2017), poplar (Wang et al. 2015), and other raw materials, to make CLT. However, it is still far from mass production and engineering applications. Due to the limitations of small log diameter and large dry shrinkage rate, the production cost of CLT using those species is very high without competitive advantages for commercialization.

Bamboo is a natural and renewable material, for which its rotation cycle is shorter than that of fast-growing wood (Chen et al. 2019). For some countries with abundant bamboo resources but limited wood resources, such as China, it is of practical significance to replace wood with bamboo (Lou et al. 2010). Bamboo is characterized by a high strength, toughness and a small shrinkage rate; moreover, bamboo is widely used in construction and other fields (Sharma et al. 2015; Wang et al. 2018). Two typical products of engineered bamboo are bamboo scrimber and laminated bamboo (Sharma et al. 2014). The former consists of crushed bamboo fibre bundles that are saturated in resin (resin content: 15 to $30 \%$ ) and compressed into a dense block (density: 1.05 to $1.25 \mathrm{~g} / \mathrm{cm}^{3}$ ) (Liu et al. 2017). Clearly, this product is less environmentally friendly with reduced specific strength. For the latter, its manufacturing process is relatively complex, wherein round bamboo culm must be split into strips, planed, bleached, laminated, and consolidated into a board. In addition, the inner and outer layers of the strips have to be removed to ensure performance uniformity of the final product, resulting in a lower utilization rate (less than 40\%) (Sharma et al. 2015; Penellum et al. 2018). Thus, it is essential to develop novel engineered bamboo products or adopt new technologies to overcome the deficiencies in existing products. Developing bamboo-wood composites is an effective way to retain and fully utilize the properties of bamboo (Tian et al. 2017). Through reasonable design, bamboo-wood composites can achieve the goal of low density while achieving high strength and rigidity. To date, many studies have been reported on bamboo-wood composites, particularly in China, such as concrete forms, container floors, and so on (Tian et al. 2017; Sheng et al. 2019). A majority of studies have been concentrated on the relationship between the mechanical properties of bamboo-wood composites and their processing parameters; however, few studies have been conducted on the optimal design of such composites to increase both their performance and value recovery.

The surface of bamboo tends to be waxy and the bamboo is also too hard and dense to be permeated by adhesives, so that interfacial failure often occurs between bamboo and wood (Yang et al. 2021). In order to improve the bonding performance of bamboo-wood composites, two ways can be selected. First, specialized adhesives can be used. Emulsion polymer isocyanate (EPI) contains isocyanate component, which can effectively bond waxy materials. Second, the surface modification of bamboo is also commonly used, including chemical treatment and physical treatment. Chemical treatment has included 
alkali treatment (Zhang et al. 2013), acid treatment (Gao et al. 2012), $\mathrm{H}_{2} \mathrm{O}_{2}$ treatment (Zhang et al. 2014), coupling agent treatment (Ren et al. 2009), etc. The physical treatment has included sanding treatment, high temperature heat treatment ( $\mathrm{Yu}$ et al. 2006), plasma treatment (Zhou et al. 2017b), and so on. Among these methods, sanding is relatively simple and cost-effective, such that it is widely used in manufacturing.

Over the past several years, the authors' research team has pioneered the research and development of bamboo-wood CCLT products (Wei et al. 2019). Bamboo-wood CCLT can obtain higher specific stiffness and strength than generic wood CLT. In previous work, resin-impregnated bamboo strips were first processed into parallel strand bamboo (PSB) or bamboo parallel strand lumber (PSL) by hot pressing. Then they were crosslaminated with Canadian hemlock lumber (commonly used as raw material for solid wood products in Canada) to form PSB-wood CCLT. Similar to bamboo scrimber, PSB requires a substantial amount of resin; thus, this product may not be cost-effective. Barreto et al. (2019) used small wood chips $(320 \mathrm{~mm} \times 40 \mathrm{~mm} \times 9 \mathrm{~mm})$ and bamboo strips $(900 \mathrm{~mm} \times$ $40 \mathrm{~mm} \times 9 \mathrm{~mm}$ ) to make "bamboo-wood-bamboo" CCLT. Although the bending modulus of elasticity (MOE) and strength of this product were $13310 \mathrm{MPa}$ and $65 \mathrm{MPa}$, respectively, the layer element used in the CLT manufacturing seemed to be too small, resulting in thin CLT not suited for structural applications.

The concept of bamboo flattening technology can be traced back to the 1980s. With the continuous efforts devoted to this technology, the seamless flattening of bamboo culm has now been commercialized (Chen et al. 2019). Bamboo flattening is a novel way to increase the utilization rate of bamboo and help develop value-added products. This work proposes a new concept of bamboo-wood CCLT, in which rectangular flattened bamboo is integrated with wood lumber to form a new bamboo-wood CCLT. In contrast to previous works (Barreto et al. 2019; Wei et al. 2019a), this study adopted a "wood-bamboo-wood" structure for CCLT based on the following reasons. First, according to previous research, the rolling shear resistance of flattened bamboo-wood CCLT with lumber used as the transverse layer was relatively low. Second, wood has a more beautiful surface texture and better aesthetic attraction than bamboo. In addition, wood is warmer and has a better environmental effect than bamboo. Furthermore, although the strength of bamboo is higher than that of wood, it can be expected that the bending strength of flattened bamboo-wood CCLT can be improved when flattened bamboo is placed on the outer layer for floor or roof applications. However, if flattened bamboo-wood CCLT is used as an element of walls, columns, and headers, the "wood-bamboo-wood" structure may have more advantages. Thus, the purpose of this work was to explore the feasibility of a novel flattened bamboowood CCLT made from flattened bamboo as the core layer and Canadian hemlock lumber as the outer layers and then to investigate the performance and failure modes of the resulting CCLT columns and headers.

\section{EXPERIMENTAL}

\section{Raw Materials}

Two raw materials were used to make the flattened bamboo-wood CCLT in this work: flattened bamboo and hemlock dimension lumber. To eliminate the residual bending stress in the flattened bamboo, as shown in Fig. 1, 3-ply cross-laminated flattened bamboo (CLB) bonded with emulsion polymer isocyanate (EPI) was adopted. EPI is commonly used in CLT manufacturing (Lu et al. 2018). The CLB, purchased from Sanming, Fujian, 
China, had dimensions of $610 \times 90 \times 19 \mathrm{~mm}^{3}$ and a moisture content (MC) of $12 \%$. Its flatwise bending MOE was $18135 \mathrm{MPa}$ [standard deviation (SD): $2151 \mathrm{MPa}$, and its bending strength was $155 \mathrm{MPa}$ (SD: $13 \mathrm{MPa}$ ). In comparison, its edgewise bending MOE was $12143 \mathrm{MPa}$ with an SD of $960 \mathrm{MPa}$, and its bending strength was $124 \mathrm{MPa}$ with an $\mathrm{SD}$ of $12 \mathrm{MPa}$. Canadian western hemlock lumber No. 2 \& better (Btr) $20 \mathrm{ft}(6 \mathrm{~m})$ long 2 $\times 6$-in $(38 \mathrm{~mm} \times 140 \mathrm{~mm})$ was used to manufacture flattened bamboo-wood CCLT in this work. The average MC of this lumber was $13 \%$. The adhesive used for the flattened-wood CCLT was a commercial single-component polyurethane (PUR; H.B. Fuller, Guangzhou, China).
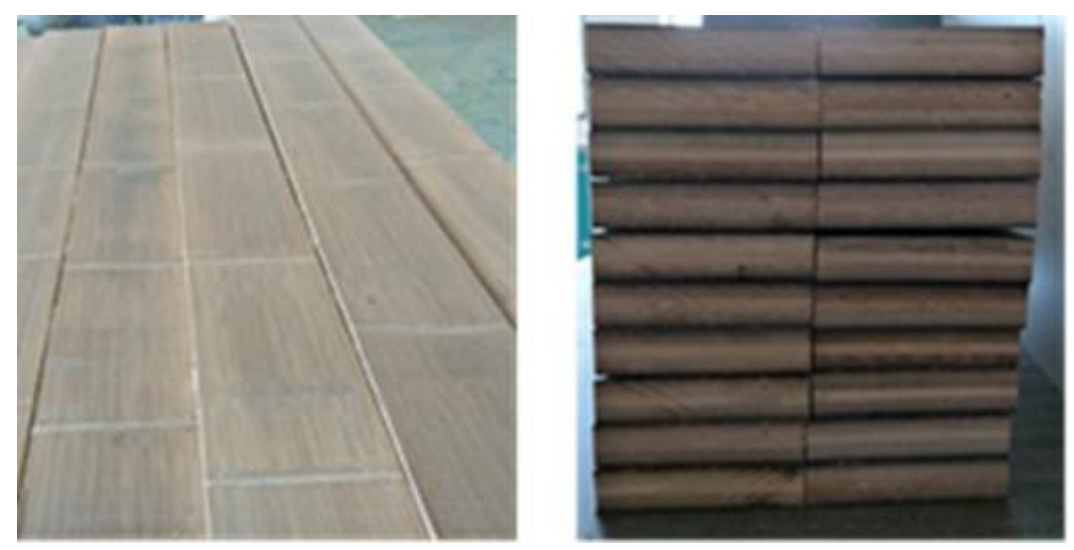

Fig. 1. Three-ply cross-laminated flattened bamboo (CLB) (the fiber direction of both outer layers of the CLB was perpendicular to the inner layer)

\section{Specimen Preparation}

Both sides of the CLB were sanded to remove approximately $0.5 \mathrm{~mm}$ of material; the final thickness of the CLB was $18 \mathrm{~mm}$. As shown in Fig. $2 \mathrm{a}$ and $2 \mathrm{~b}$, the transverse layer of the bamboo-wood CCLT was CLB, whereas the parallel layer was hemlock lumber. Note that the fiber direction of both outer layers of the CLB was perpendicular to the wood layers of bamboo-wood CCLT. Three bamboo-wood CCLT panels were made with the following processing parameters: PUR adhesive application rate of $160 \mathrm{~g} / \mathrm{m}^{2}$; pressing time of $1 \mathrm{~h}$; and cold pressure of 1.0 MPa. After storing and edge trimming, the final bamboowood CCLT had dimensions of $4200 \times 1100 \times 88 \mathrm{~mm}^{3}$.

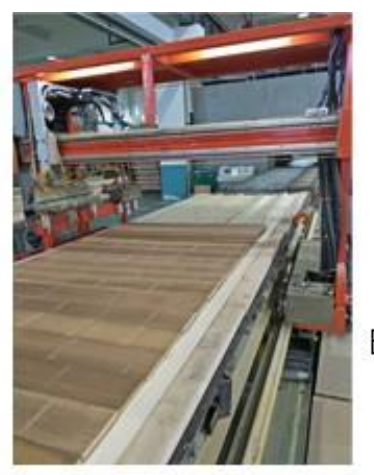

(a) Three-ply CLB as the transverse layer of bamboo-wood CCLT

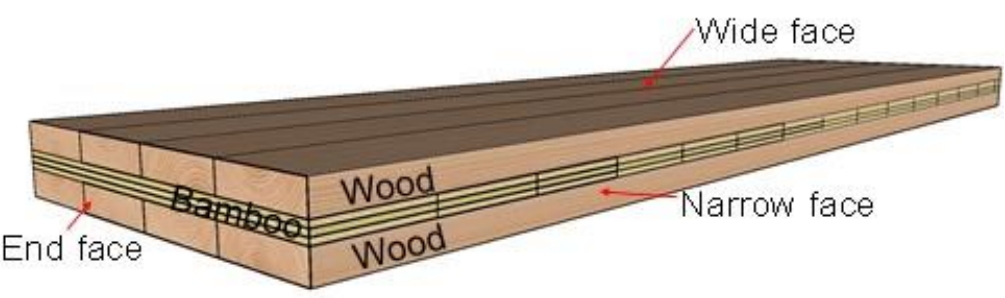

(b) Bamboo-wood CCLT configuration

Fig. 2. CLB-wood CCLT 
The CLB-wood CCLT panels were further cut into three types of column components (cross section $=105 \mathrm{~mm} \times 88 \mathrm{~mm}$ ) with the following three different heights: $210 \mathrm{~mm}, 420 \mathrm{~mm}$, and $630 \mathrm{~mm}$. Those CCLT columns (CCCs) were designated as CCC210, CCC-420, and CCC-630, respectively. In total, six CCC-210, six CCC-420, and three CCC-630 specimens were cut for this study.

In addition to column specimens, beams and headers of CLB-wood CCLT were also prepared. One CLB-wood CCLT beam $\left(88 \times 305 \times 2820 \mathrm{~mm}^{3}\right)$ specimen was cut from each of the three panels for a third-point flatwise bending test. Likewise, one CLB-wood CCLT header $\left(88 \times 150 \times 3000 \mathrm{~mm}^{3}\right)$ specimen was also cut from each of the three panels for a third-point edgewise bending test. In addition, three short beam specimens with dimensions of $88 \times 305 \times 704 \mathrm{~mm}^{3}$ were prepared for a short-span center-point bending test to explore the interlaminar shear strength of the CLB-wood CCLT.

\section{Axial Compression Test of the CCC Specimens}

Two strain gauges were affixed to each specimen in the longitudinal and transverse directions to test the compressive MOE and Poisson's ratio of CCC specimens, as described in the previous study (Wei et al. 2019b). At the interlaminar gap of the narrow face of CCC specimens, the longitudinal strain gauge and transverse strain gauge were positioned to form an "L" (Fig. 3a). However, the strain gauges formed a " $T$ " perpendicular to each other on the wide face of CCC specimens (Fig. 3a).

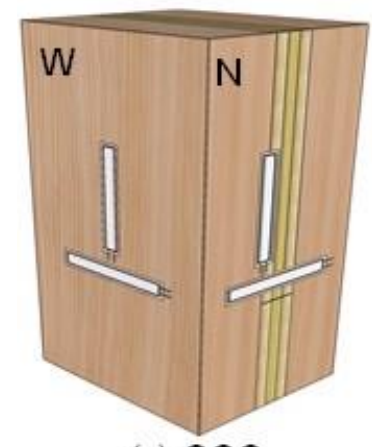

(a) $\mathrm{CCC}$

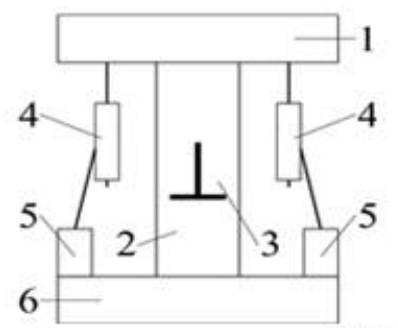

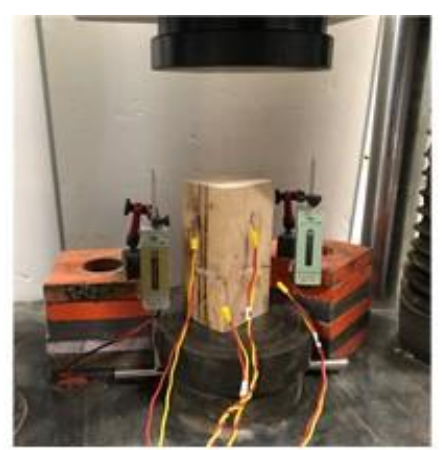

(b) Compression experiment

1 Top plate of load machine 2 Column specimen

3 Strain gauge

4 LVDT displacement sensor

5 Magnet base

6 Bottom plate of load machine

(c) Test scheme

Fig. 3. Column specimens and test setup

To appropriately match the different sizes of the CCC specimens, strain gauges with a dimension of $50 \mathrm{~mm} \times 5 \mathrm{~mm}$ (SZ120-50AA/DX, a sensitivity coefficient of 2.018 $\pm 0.10 \%$, and an electrical resistance of $120 \pm 0.2 \% \mathrm{X}$ ) were selected for the CCC-210 specimens. For the CCC-420 and CCC-630 specimens, the dimension of the longitudinal strain gauges (SZ120-100AA/DX) was $100 \mathrm{~mm} \times 5 \mathrm{~mm}$ with a sensitivity coefficient of $2.05 \pm 0.23 \%$ and an electrical resistance of $120 \pm 0.2 \% \mathrm{X}$. The dimensions of the transverse 
strain gauges were also $50 \mathrm{~mm} \times 5 \mathrm{~mm}$. Strain gauges used in this work were all produced by the Jinli Sensing Component Co., Ltd., located in Xingtai, China. The setup in this work was the same as that used in the previous work (Wei et al. 2019b). For each specimen, the narrow face and wide face were denoted by $\mathrm{N}$ and $\mathrm{W}$, respectively.

According to GB/T 50329 (2012) and ASTM D198-15 (2015), the loading scheme was performed. The preload was linearly cycled five times between 20 and $45 \mathrm{kN}$ at 1.0 $\mathrm{kN} / \mathrm{s}$, and then reduced to zero. For the formal loading stage, the load control mode was first selected. When the load increased linearly to $80 \%$ of its estimated ultimate load (210 $\mathrm{kN}$ ) with a rate of $1.0 \mathrm{kN} / \mathrm{s}$, displacement control with a rate of $0.5 \mathrm{~mm} / \mathrm{min}$ was selected.

\section{Bending Test of Bamboo-Wood CCCL Beams and Headers}

In this test, the spans of the CCLT beams and headers were 2640 and $2700 \mathrm{~mm}$, respectively. Two strain gauges were arranged at the center-point of the upper and lower surfaces of the test specimens, and the other five strain gauges were equally spaced at the mid-span section along the height direction (Fig. 4a and b). Moreover, a laser displacement meter was placed in the mid-span to examine the deflection of the specimen. One $100 \mathrm{kN}$ electrohydraulic servo test machine (Bangwei Electromechanical Control Engineering Co., Ltd., Hangzhou, China) was used in this study, and the load, displacement, and strain data were collected using a TDS-530 datalogger (highest resolution: $0.1 \mu \varepsilon$; sampling frequency: $2500 \mathrm{~Hz}$ ) (Tokyo Institute of Testing, Tokyo, Japan). Here, the term $\mu \varepsilon$ is $10^{-6}$ times the dimensionless relative change in strain, often shown as a ratio of length units. In the formal loading stage, the entire loading process was controlled by displacement until the specimen was damaged. For the beams, the preloading system was cycled 5 times between $4 \mathrm{kN}$ and $8 \mathrm{kN}$, and then loaded under displacement control at $0.5 \mathrm{~mm} / \mathrm{min}$. For the headers, the preloading system was cycled 5 times between 3 and $6 \mathrm{kN}$ and then loaded under displacement control at $0.5 \mathrm{~mm} / \mathrm{min}$.

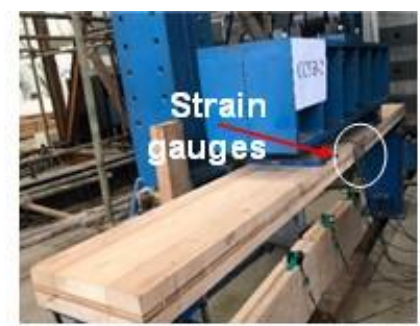

(a) Third-point flatwise bending test of a beam

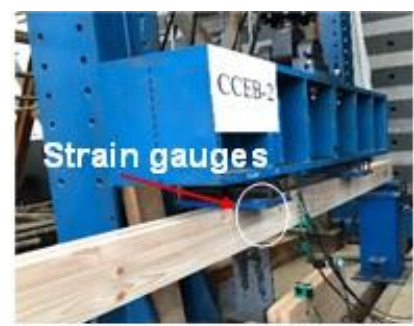

(b) Third-point edgewise bending test of a header

Fig. 4. Third-point bending tests for bamboo-wood CCLT beams and headers

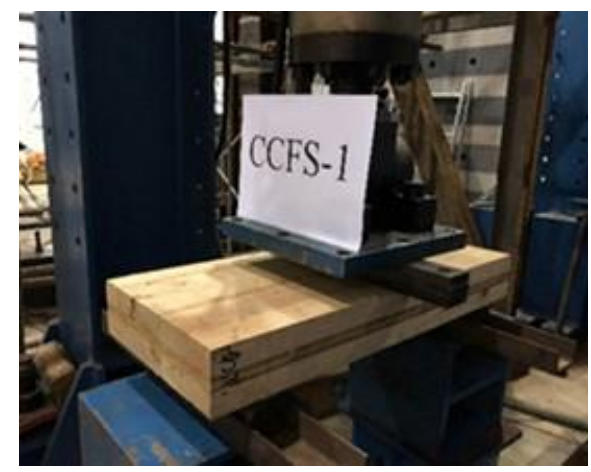

Fig. 5. Interlaminar test of a bamboo-wood CCLT beam 
In accordance with ANSI/PRG 320 (2019) and ASTM D198-15 (2015), an interlaminar shear test of the bamboo-wood CCLT beam was conducted using a short-span center-point bending test. The span was 6 times the thickness of the beam, which was 528 $\mathrm{mm}$ (as shown in Fig. 5).

\section{RESULTS AND DISCUSSION}

\section{Axial Compression of the Bamboo-wood CCC Specimens}

According to the calculation method in the previous work (Wei et al. 2019b), the axial compression MOE values and strength of CCCs with three different heights were obtained, as listed in Table 1. To better understand the CCCs, the compressive properties of 3-ply hemlock CLT columns (HCCs) as the control are also listed in Table 1. The compressive strength of the CCC specimens was smaller than that of HCC specimens of the same height. It should be noted that the strength represents the local performance of the material, and the strength of bamboo was higher than that of the wood. Therefore, when the CCC specimen failed under compression, partial failure of the wood generally occurred. In addition, the coefficient of variation $(\mathrm{COV})$ of the compressive strength of the $\mathrm{CCC}$ specimens was greater than that of the HCC specimens due to the property deviation between the bamboo and wood, which increased the variability in the column components. However, the MOE of the CCC specimens was higher than that of the HCC specimens of the same height because the elastic modulus represents the overall performance of the product. The bamboo fibers were generally longer and straight, and the corresponding specific compressive MOE along the grain was relatively larger than that of the wood; hence, the compressive MOEs of CCC specimens were higher than those of the HCC specimens.

Table 1. Compressive Properties of the CCC and HCC

\begin{tabular}{|c|c|c|c|c|}
\hline \multirow{2}{*}{ Column Type } & \multicolumn{2}{|c|}{ Compressive Strength } & \multicolumn{2}{c|}{ Compressive MOE } \\
\cline { 2 - 5 } & Mean (MPa) & COV & Mean (MPa) & COV \\
\hline CCC-210* & 23.47 & $15.22 \%$ & 9366.13 & $8.53 \%$ \\
\hline CCC-420* & 22.30 & $9.47 \%$ & 8872.67 & $5.75 \%$ \\
\hline CCC-630* & 18.32 & $9.68 \%$ & 8402.77 & $9.32 \%$ \\
\hline $\begin{array}{c}\text { HCC-210** } \\
\text { (Wei et al. 2019b) }\end{array}$ & 23.92 & $7.22 \%$ & 7255.90 & $6.08 \%$ \\
\hline $\begin{array}{c}\text { HCC-420** } \\
\text { (Wei et al. 2019b) }\end{array}$ & 24.27 & $5.14 \%$ & 6964.37 & $5.46 \%$ \\
\hline
\end{tabular}

${ }^{*} \mathrm{CCC}$ represents the bamboo-wood CCLT column, and the value is the column height;

${ }^{* *} \mathrm{HCC}$ represents the control hemlock CLT column, and the value is the column height

According to Table 1, as the column height increased from 210 to $420 \mathrm{~mm}$, the compressive strength and MOE of the CCC specimens decreased $4.99 \%$ and $5.27 \%$, respectively. As the column height increased from 420 to $630 \mathrm{~mm}$, the compressive strength and MOE of CCC specimens decreased $17.85 \%$ and $5.30 \%$, respectively. It was apparent that the column height had an effect on the compressive properties of the CCC specimens, but the statistical significance of this effect still requires further investigation. Table 2 lists the variance analyses (VA) of the effect of the column height on the compression of the CCC specimens. The results showed that the column height had no 
significant effect on the compression strength $(\mathrm{p}=0.231>0.05)$ or compression MOE for the CCC specimens $(\mathrm{p}=0.170>0.05)$. Therefore, the compressive strength and MOE of the CCC specimens, which were obtained by averaging the relative values of the three different CCC specimens, were 21.37 and $8880.52 \mathrm{MPa}$, respectively.

Table 2. VA of the Effect of the Column Height on the Compression of the CCC Specimens

\begin{tabular}{|c|c|c|c|c|c|c|c|}
\hline \multirow{2}{*}{ Column Type } & \multirow{2}{*}{ DOF } & \multicolumn{3}{|c|}{ Axial Compressive Strength } & \multicolumn{3}{|c|}{ Axial Compressive MOE } \\
\hline & & SD & $\mathrm{F}$ & $p$ & SD & $\mathrm{F}$ & $p$ \\
\hline CCC-210 & \multirow{3}{*}{14} & 3.57 & \multirow{3}{*}{3.515} & \multirow{3}{*}{$\begin{array}{c}0.231 \\
(p>0.05)\end{array}$} & 798.75 & \multirow{3}{*}{2.056} & \multirow{3}{*}{$\begin{array}{c}0.170 \\
(p>0.05)\end{array}$} \\
\hline CCC -420 & & 2.11 & & & 510.27 & & \\
\hline CCC-630 & & 1.77 & & & 783.29 & & \\
\hline
\end{tabular}

As shown in Table 3, the average Poisson's ratio of the narrow surface of the CCC specimens was 0.462 (absolute value), which was much lower than that of the HCC specimens, and the COV of the CCC specimens (22.72\%) was much lower than that of the HCC specimens. According to the previous studies, the transverse deformation caused by loading along the grain for bamboo was small, and the corresponding Poisson's ratio was 0.3, as per CECS 435 (2016). In contrast, the radial deformation caused by loading along the grain for western hemlock was large, and the corresponding Poisson's ratio was 0.485 (Kretschmann 2010). The Poisson's ratio of the narrow face of the CCC specimens was between that of hemlock and bamboo. On the wide face, the tangential deformation due to the loading along the grain for western hemlock was 0.423 , and there were inevitable cracks between the lumber layers due to the presence of the butt joint of several sawn lumber pieces in the width direction, which can increase the tangential deformation of the wide face of the CCC and HCC specimens.

Table 3. Poisson's Ratios of the CCC and HCC (Absolute Value)

\begin{tabular}{|c|c|c|c|c|}
\hline \multirow{2}{*}{ Column Type } & \multicolumn{2}{|c|}{ Narrow Face } & \multicolumn{2}{c|}{ Wide Face } \\
\cline { 2 - 5 } & Mean & COV & Mean & COV \\
\hline CCC & 0.462 & $22.72 \%$ & 0.508 & $19.35 \%$ \\
\hline HCC & 0.753 & $40.20 \%$ & 0.576 & $38.76 \%$ \\
\hline
\end{tabular}

\section{Model Analysis of the Relationship Between the Axial Compressive Stress and Strain}

Table 4 lists the data of the axial compression of the CCC specimens. Based on the data, the model of the relationship between the axial compressive stress and strain was developed (Eq. 1). One linear function in this work was used to describe the range of elasticity, and one constant function was used to describe the plastic range. Additionally, a quadratic function was used to describe the elastic-plastic range,

$$
\sigma(\varepsilon)=\left\{\begin{array}{lc}
\alpha \varepsilon & 0<\varepsilon \leq \varepsilon_{\mathrm{ce}} \\
\beta_{1} \varepsilon^{2}+\beta_{2} \varepsilon+\beta_{3} & \varepsilon_{\mathrm{ce}}<\varepsilon \leq \varepsilon_{\mathrm{cu}} \\
\gamma \sigma_{\mathrm{cu}} & \varepsilon>\varepsilon_{\mathrm{cu}}
\end{array}\right.
$$

where $\varepsilon_{\mathrm{cu}}$ represents the ultimate strain, $\sigma_{\mathrm{cu}}$ represents the ultimate stress, $\varepsilon_{\mathrm{ce}}$ represents the strain value, $\sigma_{\text {ce }}$ represents the ultimate strength, wherein $\varepsilon_{\text {ce }}$ is defined as $0.60 \varepsilon_{\mathrm{cu}}$ in this work; and $\alpha, \beta_{1}, \beta_{2}, \beta_{3}$, and $\gamma$ are coefficients. Each coefficient can 
be obtained based on the boundary conditions. According to the calculation method in the previous work Wei et al. (2019b), $\alpha, \beta_{1}, \beta_{2}, \beta_{3}$, and $\gamma$ can be obtained.

Table 4. Characteristic Constants of CCC Specimens During Axial Compression

\begin{tabular}{|c|c|c|c|c|c|c|}
\hline $\begin{array}{c}\text { Specimen } \\
\text { No. }\end{array}$ & $\varepsilon_{\mathrm{cu}}\left(10^{-6}\right)$ & $\sigma_{\mathrm{cu}}(\mathrm{MPa})$ & COV & $\varepsilon_{\text {ce }}\left(10^{-6}\right)$ & $\sigma_{\mathrm{ce}}(\mathrm{MPa})$ & Mean \\
\hline CCCa-1 & 5418 & 22.77 & \multirow{15}{*}{$14.72 \%$} & 1579.60 & 13.66 & \multirow{15}{*}{$\begin{array}{c}\varepsilon_{\mathrm{cu}}=3483.68 \\
\sigma_{\mathrm{cu}}=21.97 \\
\varepsilon_{\mathrm{ce}}=1503.22 \\
\sigma_{\mathrm{ce}}=13.18\end{array}$} \\
\hline CCCa-2 & 3815 & 19.56 & & 1561.46 & 11.74 & \\
\hline CCCa-3 & 5247 & 26.02 & & 1708.51 & 15.61 & \\
\hline CCCa-4 & 3200 & 28.56 & & 1642.12 & 17.13 & \\
\hline CCCa-5 & 2657 & 19.61 & & 1109.61 & 11.76 & \\
\hline CCCa-6 & 2828 & 24.28 & & 1322.66 & 14.57 & \\
\hline CCCb-1 & 2037 & 18.76 & & 1128.82 & 11.25 & \\
\hline $\mathrm{CCCb}-2$ & 3817 & 23.32 & & 1878.82 & 13.99 & \\
\hline CCCb-3 & 4213 & 25.18 & & 1734.64 & 15.11 & \\
\hline CCCb-4 & 2683 & 22.46 & & 1495.27 & 13.48 & \\
\hline CCCb-5 & 2626 & 21.69 & & 1484.22 & 13.01 & \\
\hline CCCb-6 & 5198 & 22.36 & & 1798.04 & 13.42 & \\
\hline CCCc-1 & 3165 & 20.27 & & 1425.83 & 12.16 & \\
\hline CCCc-2 & 2708 & 16.81 & & 1329.12 & 10.09 & \\
\hline CCCc-3 & 2642 & 17.87 & & 1349.55 & 10.72 & \\
\hline
\end{tabular}

A comparison between the actual stress-strain curve and the stress-strain curve from the model is shown in Fig. 6. The simulated curve from the proposed stress-strain model was in good agreement with the actual stress-strain curve of the CCC specimens during axial compression.

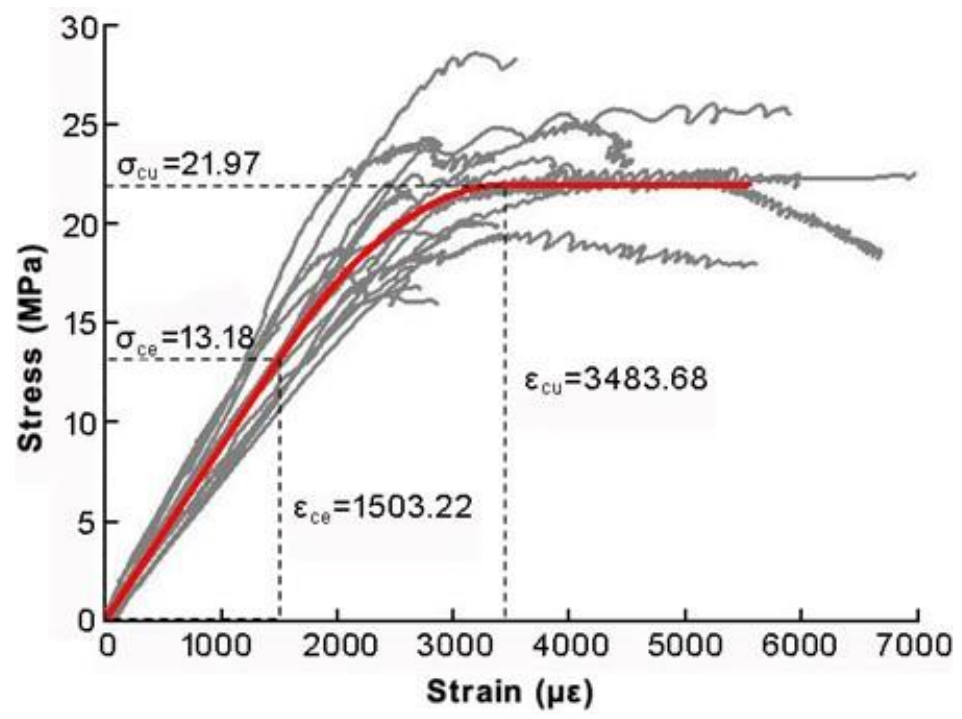

Fig. 6. Comparison between the actual stress-strain curve and the stress-stress model

The CCC specimens exhibited a complicated failure mode, among which nearly each specimen exhibited a mixed failure mode. The typical failure modes for the CCC specimens with the three different heights are shown in Fig. 7. There were four comprehensive failure modes: end-crushing damage (indicated by an ellipse), longitudinal 
cracking damage (indicated by a rectangle), cracking at the knot (represented by a fivepointed star), and oblique shear failure (represented by a circle). The failure modes in the narrow faces were substantially different from those in wide faces of the CCC specimens, and the failure modes were in general more complex for the shorter column specimens than those of the longer column specimens; these results are different from those of CLT and glued-laminated timber (GLT) columns (Wei et al. 2019b). Clearly, the end-crushing failures and the oblique shear failures were mostly accompanied by longitudinal cracking damage at the bonding interface for the narrow faces of the CCC specimens [Fig. 7a1, a2, and $\mathrm{a} 3$ ( $\mathrm{N}$ face) and Fig. 7b1, b2, and b3 ( $\mathrm{N}$ face)], which was similar to CLT columns (Wei et al. 2019b). However, the failure modes of CCC specimens were more complicated than those of the HCC specimens due to the core layer of bamboo. Notably, when a CCC specimen was used to bear axial compression, longitudinal cracking was prone to occur. Therefore, a CCC specimen must be circumferentially reinforced with fiber-reinforced polymer (FRP) or steel plates when used.

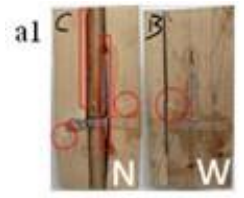

bl

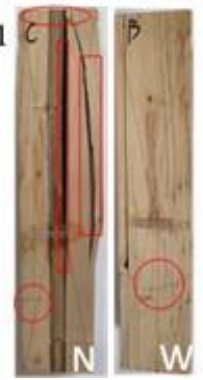

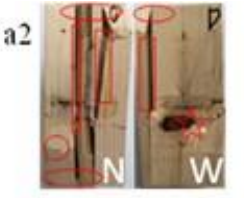

b2

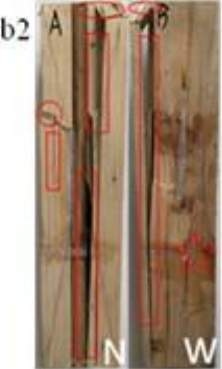

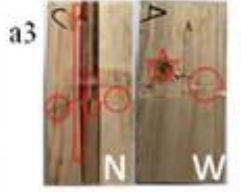

b3

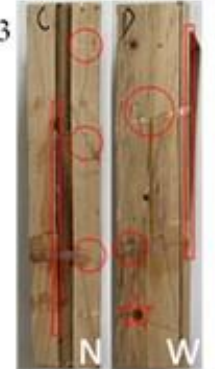

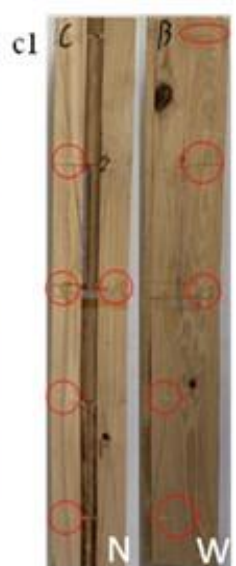

Fig. 7. Failure modes of the CCC specimens

\section{Third-point Bending Tests of the Bamboo-wood CCLT Beams and Headers}

Table 5 lists the third-point bending test results of the bamboo-wood CCLT beams and headers in the major strength direction. Some test data of three-layer CLT using the No. 2 hemlock lumber were taken from a previous study (Gao 2017). The flatwise bending MOE and strength of the CCLT beam in the major strength direction were slightly higher than those of the control hemlock CLT beams. In comparison, the bending MOE and strength of the CCLT headers were $17.34 \%$ less and $16.17 \%$ greater than those of the CCLT beams, respectively. This phenomenon may be due to the fact that the flattened bamboo without edge bonding had difficulty in forming integrity and had little contribution to the stiffness of the CCL header; however, the ductile effect of CLB blocks may improve the strength of the CCL header.

Table 5. Third-point Bending Results of CLT Beams and Headers

\begin{tabular}{|c|c|c|c|}
\hline Beam & $P_{\max }-$ mean $(\mathrm{kN})$ & MOE-mean $(\mathrm{MPa})$ & MOR $^{*}$-mean $(\mathrm{MPa})$ \\
\hline CCLT (beam) & 32.91 & 10915.05 & 37.29 \\
\hline CCLT (header) & 31.27 & 9021.81 & 43.32 \\
\hline $\begin{array}{c}\text { Hemlock CLT (beam) } \\
\text { (Gao 2017) }\end{array}$ & 36.87 & 10667.77 & 34.78 \\
\hline
\end{tabular}

${ }^{*}$ MOR represents the modulus of rupture 
Figure 8 shows the typical load-deflection curves in the mid-span of the CCLT beams and headers. The failure development in the CCLT beams and headers can be roughly divided into three stages. The first stage was the elastic stage, in which the midspan deflection increased with increasing load and the slope of the load-deflection curve remained basically unchanged. The second stage was the elastic-plastic stage. When the load reached the maximum value of the elastic stage, the mid-span deflection accelerated with increasing load, and the slope of the load-deflection curve began to decrease gradually, especially with the headers. At this time, sounds corresponding to wood fibre and bamboo fibre fractures began to emanate from the tension zone of the specimen, and there was a trend of cracking at the mid-span bonding interface. The third stage was the failure stage. For the CCLT beams, when the ultimate load was reached, the beam suddenly cracked with the corresponding sound emanating from the middle part of the beam bottom, and the loaddeflection curve presented a steep decline. The failure pattern of the CCLT header was a typical bending brittle failure, which occurred in the tension zone of the specimen. However, the bearing capacity of the CCLT header decreased rapidly after reaching the peak load, and this decline occurred drastically. This phenomenon occurred because the bamboo, which has higher toughness than the wood, used as the perpendicular layer of the CCLT header can still bear a certain load after the wood failed. The header absorbed energy through bamboo deformation; as the deformation increased, the bamboo fibres tore, and the bearing capacity decreased. The bamboo continued to deform and absorb energy until the header was completely destroyed and lost its bearing capacity. Clearly, the CCLT headers exhibited a mode of plastic failure.

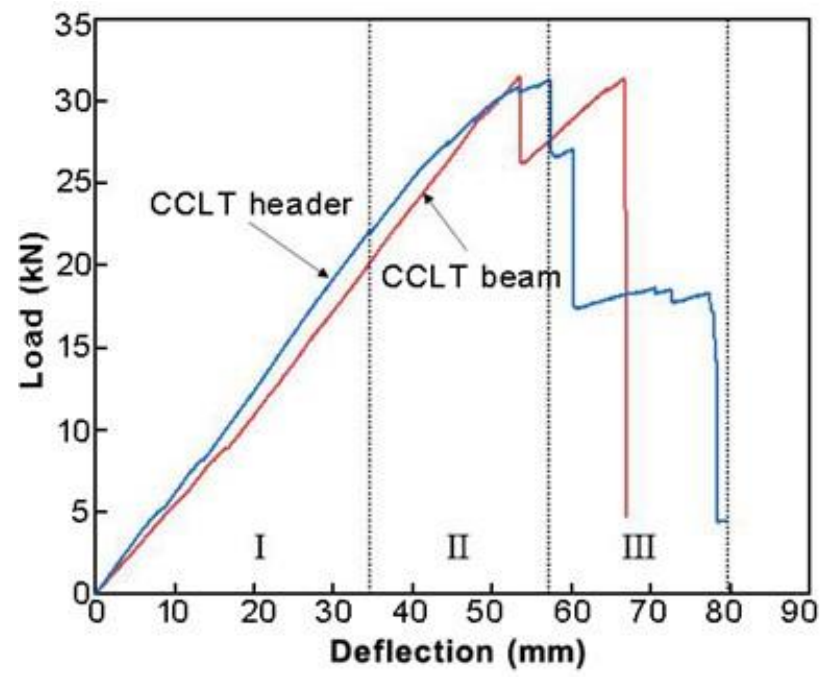

Fig. 8. Typical load-deflection curves in the mid-span of the CCLT beams and headers

Figure 9 shows the failure mode of a bamboo-wood CCLT beam. It was observed that the tensile failure started first in the parallel layer of lumber (ellipse in Fig. 9), after which the crack rapidly expanded to the bamboo-wood bonding interface, causing the interface failure, and finally leading to a loss of bearing capacity of the beam. Clearly, the typical rolling shear failure found in CLT did not appear during bending, which was because the CLB used as the perpendicular layer did not have the annual ring structure of wood. 


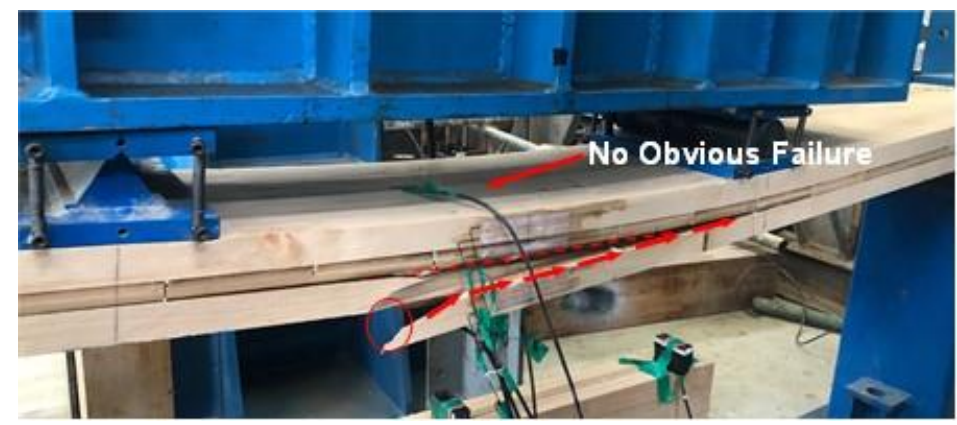

Fig. 9. Typical failure mode of CCLT beams

Figure 10 shows the failure mode of a bamboo-wood CCLT header. Compared to the CCLT beams, the CCLT headers exhibited a more complicated failure mechanism. Similar to the results discussed above, the failure process in the CCLT headers also began with tensile surface fractures (ellipse in Fig. 10b). However, the header did not immediately lose its bearing capacity. The cracks in the tensile zone expanded to the bonding interface of the bamboo and wood, resulting in delamination (dotted line in Fig. 10b) and bearing failure of the wood. The stress in the mid-span of the header was redistributed, and an obvious compressive failure occurred in the compression zone of the header (as shown in Fig. 10c). Clearly, macro cracks of the CLB gradually developed in the tension zone of the CCLT header, but cracks of CLB blocks in the compression zone were not observed.

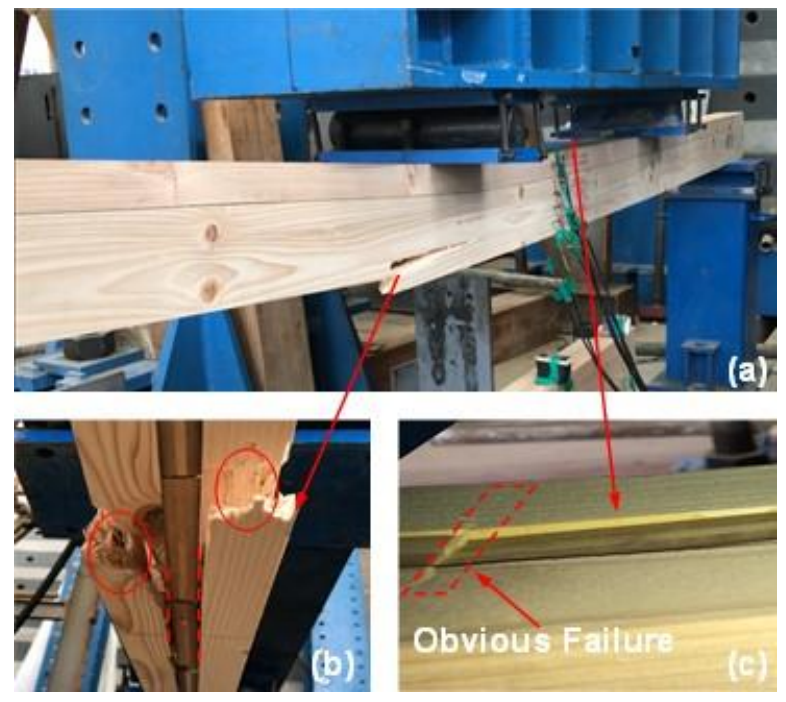

Fig. 10. Failure mode of CCLT headers. (a) the bending setup of a bamboo-wood CCLT header; (b) the failure mode of a bamboo-wood CCLT header in the bottom surface; (c) the failure mode of a bamboo-wood CCLT header in the top surface

\section{Short-span Bending Test of the CCLT Beams}

The average interlaminar shear strength of the flattened bamboo-wood CCLT beams was $2.47 \mathrm{MPa}$, which was slightly higher than that of bamboo PSL-wood CCLT counterparts (2.38 MPa) reported in a previous work (Wei et al. 2019a). In the previous study, the core layer of the bamboo PSL-wood CCLT beams was composed of hemlock lumber. For these specimens, shear failure generally started with interfacial bonding failure between the bamboo and wood, and then rolling shear failure occurred in the core wood 
layer. However, because the flattened bamboo was used as the core layer in this work, no rolling shear failure was observed. Instead, the bonding interface between the bamboo and wood was first damaged, and the crack extended from the interface to the tensile zone of the beam. Hence, the flattened bamboo, when used as the perpendicular layer of the CLT beams, can provide a good resistance to rolling shear.

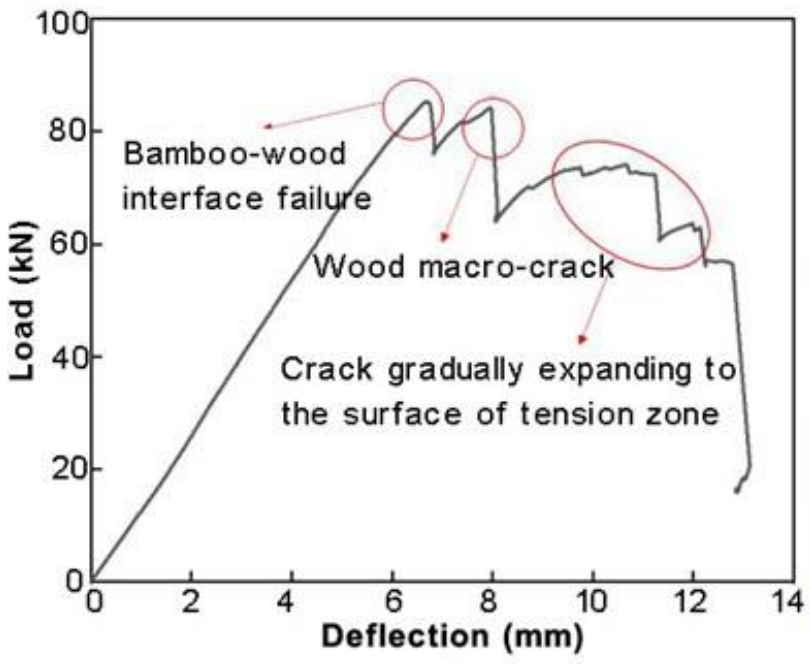

(a) a load-deflection curve

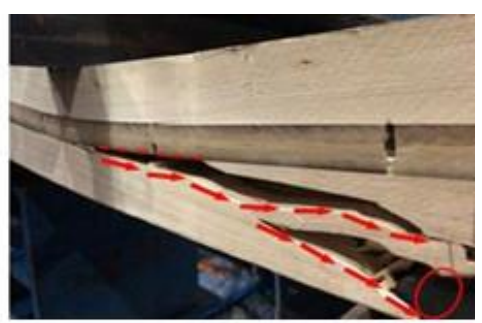

(b) failure mode of the CCLT beam

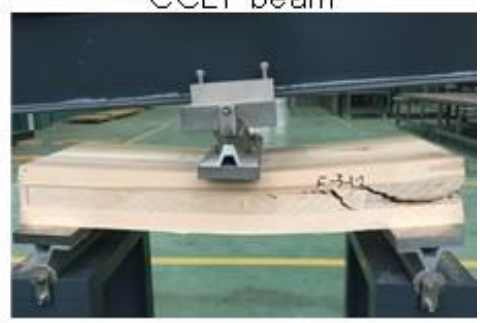

(c) failure mode of the wood CLT beam (Gao 2017)

Fig. 11. A typical example of a load-deflection curve of the CCLT beam and a comparison of failure modes of the CCLT and wood beams under short-span bending

\section{CONCLUSIONS}

In this work, a novel bamboo-wood composite cross-laminated timber (CCLT) was developed, in which CLB was used as the perpendicular layer and Canadian western hemlock lumber was used as the parallel layer. Through static axial compression tests, third-point bending tests, and short-span bending tests, the failure mechanisms of the new CCLT were investigated, and the corresponding performance under compression, bending, and shear was explored. In comparison with the results from the control tests, the following conclusions can be obtained:

1. The compressive strength of the bamboo-wood CCLT columns was close to that of the control hemlock CLT counterparts at the same height, but the modulus of elasticity (MOE) of the CCLT columns was higher. The CCLT columns exhibited compressive failure of wood due to its relatively low strength.

2. The failure modes of the bamboo-wood CCLT columns were more complex than those of the control hemlock CLT counterparts. The failure process of the CCLT columns can be divided into three ranges, i.e., elastic, elastic-plastic, and plastic, which can be described by a primary function, a secondary function, and a primary function, respectively. The axial compressive stress-strain model developed yielded a good prediction compared with the experimental results.

3. The bending modulus and strength of the bamboo-wood CCLT beams were slightly higher than those of the control hemlock CLT counterparts in the major strength 
direction. For the bamboo-wood CCLT, the bending modulus and strength of its headers were $17.34 \%$ lower and $16.17 \%$ higher than those of its beams, respectively. The development of failure can be roughly divided into three stages. The CCLT beams generally yielded a brittle failure, whereas the CCLT headers yielded a plastic failure.

4. The interlaminar shear strength of the bamboo-wood CCLT was $2.46 \mathrm{MPa}$, which is slightly higher than that of bamboo PSL-wood CCLT. The load-carrying capacity of the bamboo-wood CCLT was mainly governed by the interfacial failure between the bamboo and wood, in which no rolling shear failure was observed.

\section{ACKNOWLEDGMENTS}

The present work was financially sponsored by the science project of JSCAF (2020kj001) and Jiangsu Planned Projects for Postdoctoral Research Funds (2018K121C).

\section{REFERENCES CITED}

ANSI/APA PRG 320-2019 (2019). "Standard for performance-rated cross-laminated timber," American National Standards Institute, Washington D.C., USA.

ASTM D198-15 (2015). "Standard test methods of static tests of lumber in structural sizes," ASTM International, West Conshohocken, PA, USA.

Barreto, M. I. M., de Araujo, V., Cortez-Barbosa, J., Christoforo, A. L., and Moura, J. D. M. (2019). "Structural performance analysis of cross-laminated timber-bamboo (CLTB)," BioResources 14(3), 5045-5058. DOI: 10.15376/biores.14.3.5045-5058

Brander, R., Flatscher, G., Ringhofer, A., Schickhofer, G., and Thiel, A. (2016). "Cross laminated timber (CLT): Overview and development," European Journal of Wood and Wood Products 74, 331-351. DOI: 10.1007/s00107-015-0999-5

CECS 435-2016 (2016). "Technical specification for round bamboo-structure building," China Association for Engineering Construction Standardization, Beijing, China.

Chen, Z. X., Lei, Q., He, R. L., Zhang Z. F., and Chowdhury A. J. (2016). "Review on antibacterial biocomposites of structural laminated veneer lumber," Saudi Journal of Biological Sciences 23(1), 142-147. DOI: 10.1016/j.sjbs.2015.09.025

Chen, H., Zhang, Y. T., Yang, X., Ji, H., Zhong, T. H., and Wang, G. (2019). “A comparative study of the microstructure and water permeability between flattened bamboo and bamboo culm," Journal of Wood Science 65(1), 64-78. DOI: 10.1186/s10086-019-1842-0

Davids, W. G., Willey, N., Lopez-Anido, R., Shaler, S., Gardner, D., Edgar, R., and Tajvidi, M. (2017). "Structural performance of hybrid SPFs-LSL cross-laminated timber panels," Construction and Building Materials 149, 156-163. DOI: 10.1016/j.conbuildmat.2017.05.131

Espinoza, O., and Buehlmann, U. (2018). "Cross-laminated timber in the USA: opportunity for Hardwoods?" Current Forestry Reports 4(4), 1-12. DOI: $10.1007 / \mathrm{s} 40725-018-0071-\mathrm{x}$

GB/T 50329 (2012). "Standard for test methods of timber structures," Standardization Administration of China, Beijing, China. 
Gao, W., Luo, Y. L., Gan, W. X., Tan, Q. L., and Li, X. B. (2012). "Study on wettability of bamboo surface," Journal of Anhui Agricultural Sciences 40(35), 17322-17326. DOI: 10.13989/j.cnki.0517-6611.2012.35.035

Gao, Z. Z. (2017). Performance Evaluation and Manufacturing of Cross-Laminated Timber Made from Hemlock, Master's Thesis, Nanjing Forestry Univ., Nanjing, China.

Gong, Y. C., Wu, G. F., and Ren, H. Q. (2016). "Block shear strength and delamination of cross-laminated timber fabricated with Japanese larch," BioResources 11(4), 10240-10250. DOI: 10.15376/biores.11.4.10240-10250

He, M. J., Zhang, J., Li, Z., and Li, M. L. (2016). "Production and mechanical performance of scrimber composite manufactured from poplar wood for structural applications," Journal of Wood Science 62(5), 429-444. DOI: 10.1007/s10086-016-1568-1

Kretschmann, D. E. (2010). Mechanical Properties of Wood-Wood as an Engineering material (FPL-TR 113), U.S. Department of Agriculture, Forest Service, Forest Products Laboratory, Madison, WI, USA.

Liao, Y. C., Tu, D. Y., Zhou, J. H., Zhou, H. B., Yun, H., Gu, J., and Hu, C. S. (2017). "Feasibility of manufacturing cross-laminated timber using fast-grown small diameter eucalyptus lumbers," Construction and Building Materials 132, 508-515. DOI: 10.1016/j.conbuildmat.2016.12.027

Lou, Y. P., Li, Y. X., Kathleen, B., Giles, H., and Zhou, G. M. (2010). "Bamboo and climate change mitigation," Technical Report 32, International Network for Bamboo and Rattan, Beijing, China.

Lu, Z. H., Zhou, H. B., Liao, Y. C., and Hu, Y. C. (2018). "Effects of surface treatment and adhesives on bond performance and mechanical properties of cross-laminated timber (CLT) made from small diameter Eucalyptus timber," Construction and Building Materials 161, 9-15. DOI: 10.1016/j.conbuildmat.2017.11.027

Penellum, M., Sharma, B., and Shah, D. U., Foster, R. M., and Ramage, M. H. (2018). "Relationship of structure and stiffness in laminated bamboo composites," Construction and Building Materials 165, 241-246. DOI: 10.1016/j.conbuildmat.2017.12.166

Ren, Y. P., Wang, Z., and Wang, Z. L. (2009). "Influence of treatment of bamboo surface on adhesion performance," Adhesion in China 2, 33-37. DOI: 10.3969/j.issn.10015922.2009.02.006

Sharma, B., Gatoo, A., Bock, M., Mulligan, H., and Ramage, M. (2014). "Engineered bamboo: State of the art," Proceedings of the Institute of Civil EngineersConstruction Materials 168(CM2), 57-67. DOI: 10.1680/coma.14.00020

Sharma, B., Gatoo, A., Bock, M., and Ramage, M. (2015). "Engineered bamboo for structural applications," Construction and Building Materials 81, 66-73. DOI: 10.1016/j.conbuildmat.2015.01.077

Sheng, J. L., Chen, J. B., Wu, Q. R., Qi, W. Y., Guan, X., Li, J. P., and Lin, J. G. (2019). "Response surface optimization of hot-pressing technology for light bamboo-based concrete formwork," Journal of Forestry Engineering 4(6), 54-61. DOI: 10.13360/j.issn.2096-1359.2019.06.008

Tian, Z. P., Wang, Z. H., Zhang, Z. L., and Ren, H. Q. (2017). "Research on preparation and mechanical properties of structural bamboo-wood composite LVL," J. Anhui Agricultural Univ. 44(3), 404-408. DOI: 10.13610/j.cnki.1672-352x.20170524.012

Wang, Z. Q., Gong, M., and Chui, Y. H. (2015). "Mechanical properties of laminated strand lumber and hybrid cross-laminated timber," Construction and Building Materials 101, 622-627. DOI: 10.1016/j.conbuildmat.2015.10.035 
Wang, Z. Q., Fu, H. M., Gong, M., Luo, J. Y., Dong, W. Q., Wang, T., Chui, Y. H. (2017). "Planar shear and bending properties of hybrid CLT fabricated with lumber and LVL," Construction and Building Materials 151, 172-177. DOI: 10.1016/j.conbuildmat.2017.04.205

Wang, J. P., Matthews, M. L., Williams, C. M., Shi, R., Yang, C. M., Tunlaya-Anukit, S., Chen, H., Li, Q. Z., Liu, J., Naik, P., et al. (2018). "Improving wood properties for wood utilization through multi-omics integration in lignin biosynthesis," Nature Communications 9(1), Article Number 1579. DOI: 10.1038/s41467-018-03863-z

Wei, P. X., Wang, B. J., Wang, L. B., Wang, Y. Q., Yang, G. R., and Liu, J. H. (2019a). "An exploratory study of composite cross-laminated timber (CCLT) made from bamboo and hemlock for mix," BioResources 14(1), 2160-2170. DOI: 10.15376/biores.14.1.2160-2170

Wei, P. X., Wang, B. J., Li, H., Wang, L. B., Peng, S., and Zhang, L. (2019b). “A comparative study of compression behaviors of cross-laminated timber and gluedlaminated timber column," Construction and Building Materials 22, 86-95. DOI: 10.1016/j.conbuildmat.2019.06.139

Yang, G. R., Niu, Y., Yang, H. Z., and Wei, P. X. (2021). "Research progress on bonding properties of bamboo-wood composite interface," Journal of Northwest Forestry 36(3), 1-5. DOI: 10.3969/j.issn.1001-7461.2021.03.00

Yu, Y., Liu, R., Huang, Y., Meng, F. D., and Yu, W. J. (2017). "Preparation, physical, mechanical, and interfacial morphological properties of engineered bamboo scrimber," Construction and Building Materials 157, 1032-1039. DOI: 10.1016/j.conbuildmat.2017.09.185

Yu, W. J., Yu, Y. L., and Jiang, Z. H. (2006). "Bonding properties of bamboo surface," Journal of Bamboo Research 25(1), 30-36. DOI: 10.3969/j.issn.10006567.2006.01.008

Zhang, X. D., Cheng, X. C., Lin, L. S., Tang, Y. N., and Wu, H. (2013). "Effect on bonding performance of bamboo skin and bamboo pith through chemical processing," Journal of Nanjing Forestry University 37(4), 171-174. DOI: 10.3969/j.issn.10002006.2013.04.033

Zhang, Q. L., Zeng Q. Z., Li, Q. Y., Zhang, R. Q., and Zhou, H. W. (2014). "Effects of treatment with $\mathrm{H}_{2} \mathrm{O}_{2}$ solution on the wettability of adhesives on Phyllostachys pubescen's tangential section," Journal of Fujian College of Forestry 34(2), 184-188. DOI: 10.13324/j.cnki.jfcf.2014.02.015

Zhou, J. H., Chui, Y. H., Gong, M., and Hu, L. (2017a). "Elastic properties of full-size mass timber panels: Characterization using modal testing and comparison with model predictions," Composite Part B: Engineering 112, 203-212. DOI: 10.1016/j.compositesb.2016.12.027

Zhou, X. Y., Chen, M. Z., and Du, G. B. (2017b). "Research progress on surface modification of agriculture and forestry biomass materials by plasma treatment," Journal of Forestry Engineering 2(1), 1-7. DOI: 10.13360/j.issn.20961359.2017.01.001

Article submitted: Dec. 13, 2020; Peer review completed: May 8, 2021; Revised version received and accepted: May 21, 2021; Published: June 1, 2021.

DOI: $10.15376 /$ biores.16.3.5187-5202 